\title{
Electroconversion of atrial fibrillation after mitral valvotomy
}

\author{
Adrian R. M. Upton ${ }^{1}$ and Michael Honey ${ }^{2}$ \\ From the London Chest Hospital, London E.2
}

Of a series of 100 consecutive patients undergoing closed mitral valvotomy, 84 were in atrial fibrillation after operation. Fifty-six were treated by DC countershock; 7 returned to sinus rhythm without defibrillation, and in the remaining $2 I$ defibrillation was not attempted. Of those patients fibrillating for more than a year, none remained in sinus rhythm one year after defibrillation, and no patient remained in sinus rhythm for more than 5 weeks when atrial fibrillation had been present for 5 years before operation. A small proportion of patients in whom fibrillation had been present for less than a year, or had appeared after operation, maintained sinus rhythm for $I$ to 2 years or more: approximately one-third at I year, and one-quarter at 2 years. Threequarters of those patients in sinus rhythm before and after operation remained in sinus rhythm for 3 years. A large heart, low amplitude $\mathrm{f}$ waves, and male sex were also unfavourable features.

It is suggested that the development of atrial fibrillation is an event in the natural history of mitral stenosis which depends relatively little on the degree of stenosis or its relief by operation. Though fibrillation is sometimes precipitated by operation, defibrillation postoperatively is only rarely followed by the maintenance of sinus rhythm for more than $I$ to 2 years. The attempt to restore sinus rhythm is only worth while when atrial fibrillation has been present for less than I year.

The advantages of sinus rhythm over atrial fibrillation in chronic rheumatic heart disease are generally agreed. The incidence of arterial embolus is higher in atrial fibrillation than in sinus rhythm (Goldman, 1960; Szekely, 1964); haemodynamic improvement after reversion to sinus rhythm has been shown both in the quinidine era and since the advent of direct-current countershock (Kahn et al., 1964; Graettinger, Carleton, and Muenster, 1964; Morris et al., 1965; Benchimol, Lowe, and Akre, 1965; Killip and Baer, 1966; Resnekov, 1967). Subjectively, awareness of the heart beat, and particularly of rapid irregular palpitation, is less when the rhythm is of sinus origin. When quinidine was the accepted method of treatment for achieving reversion to sinus rhythm, it was only used in a small proportion of cases; large doses were often required and these commonly caused unpleasant side effects, with a real risk of

Received 5 February 197 I.

1 Present address: Regional Neurological Centre, Newcastle General Hospital, Westgate Road, Newcastleupon-Tyne.

${ }^{2}$ Address for reprints: Dr. M. Honey, Brompton Hospital, London S.W.3. sudden death. The drug was therefore used only where the likelihood of success was thought to be high. After the introduction of mitral valvotomy, it was recognized that patients who had had a successful operation constituted a relatively favourable group in this respect; in selected cases, reversion to sinus rhythm was achieved in 70 per cent or more of cases. A high relapse rate was reported by Bloom (1963) who found that few patients successfully converted to sinus rhythm with quinidine after valvotomy remained in normal rhythm for long, particularly when atrial fibrillation was present before operation.

The introduction of DC countershock (Lown, Amarasingham, and Neuman, 1962) provided a safe, simple, and effective method of restoring sinus rhythm. This was achieved in over 75 per cent of cases after mitral valvotomy (Oram and Davies, 1964; Towers et al., 1965; Selzer et al., 1965; Lown, 1967; Resnekov and McDonald, I968), but it was soon recognized that there was as high a relapse rate after electrical defibrillation as there was after quinidine. The advantages of the method, however, were such that reversion to sinus 
rhythm could be recommended even if it could only be expected to remain for a few months to a few years. The patient would then have the benefits of normal rhythm during this time, and if necessary, the treatment could be repeated with a minimum of inconvenience. It was desirable, therefore, to discover which patients submitted to mitral valvotomy could be expected to maintain sinus rhythm for a worth-while period after electrical reversion by DC countershock.

We embarked on a prospective survey early in 1965 in order to answer this question. The plan was to submit to electrical defibrillation all patients undergoing mitral valvotomy who remained in atrial fibrillation after operation, and to relate the length of time sinus rhythm was maintained to various factors thought to be relevant. A series of 100 patients was completed early in 1967, and all but 2 patients have now been followed for at least 3 years.

\section{Patients and methods}

The series consists of 100 consecutive patients undergoing closed mitral valvotomy between February I965 and March 1967 (Table I). In those patients with atrial fibrillation after operation, an attempt was normally made to restore sinus rhythm, not less than 3 weeks after operation; when the patient remained in hospital for 3 to 4 weeks after operation, the attempt was usually made before discharge from hospital, but otherwise the patient was readmitted either from home or after a period of convalescence. Twenty-eight patients were not defibrillated for reasons cited in Table $I$. In 10 of these, the decision not to defibrillate was made because of factors thought to make success unlikely, but this failure to implement the planned policy has not affected the results of the study.

Technique of defibrillation Digoxin was omitted for at least 24 hours before the procedure, which was delayed if there was evidence of overdigitalization or potassium depletion, as serious post-reversion arrhythmias may arise under these circumstances (Gilbert and Cuddy, 1965; Kleiger and Lown, 1966). Quinidine (200-300 mg 8hourly) was started on the day before attempted conversion; this drug has been shown to reduce the energy of the shock required to restore sinus rhythm and to increase the likelihood that sinus : rhythm will be maintained immediately afterwards (Rossi and Lown, 1967). All patients were anaesthetized using methohexitone sodium (Brietal), though, since the completion of this study, we have employed intravenous diazepam (Valium) after hyoscine premedication. Synchronized DC countershock was administered using a Cardiac - Recorders DC defibrillator. The negative electrode was applied to the chest wall over the cardiac apex and the positive electrode to the right of the upper sternum. An initial shock of 80 to roo
TABLE I Analysis of 100 patients submitted to mitral valvotomy

\begin{tabular}{ll}
\hline Preoperative rhythm: $\left\{\begin{array}{l}\text { Sinus } \\
\text { Atrial fib. }\end{array}\right.$ & 30 \\
70
\end{tabular}

joules was employed; if sinus rhythm was not restored, increasing energies were used up to a maximum of 300 to 400 joules; if ventricular arrhythmias occurred, the attempt was abandoned. Anticoagulants were not given as a routine, but were continued if the patient was already being anticoagulated. The risk of early systemic arterial embolism after successful mitral valvotomy, once the immediate postoperative period is past, is small, and no emboli occurred after defibrillation in this series. Quinidine was continued after successful reversion to sinus rhythm in a dose of 200-300 mg thrice daily; there were no arrhythmias or deaths attributable to quinidine, but when this small dose caused side effects, the prophylactic agent was changed to procainamide, or none was given. Oram and Davies (1964) and Resnekov et al. (1969) state that quinidine in this context is ineffective and may be dangerous; their results in fact suggest that quinidine may delay the return to atrial fibrillation, though the differences are not statistically significant. In a larger series, Härtel $e t$ al. (1970) found that quinidine prophylaxis, using a slow-release preparation, was effective and safe.

Analysis of results Successful defibrillation was defined as the restoration of a sinus mechanism for even a few beats; a few patients showed a junctional rhythm immediately after defibrillation, but soon afterwards reverted to a sinus mechanism. The patients were examined at regular intervals and electrocardiograms recorded; 4 patients living overseas were not seen, but reports were obtained from their physicians. A few patients, returning to atrial fibrillation, were defibrillated a second or a third time and are discussed below.

The duration of sinus rhythm after electroconversion was examined in relation to the age and sex of the patient, the duration of atrial fibrillation, the size of the heart (cardiothoracic 
ratio), the magnitude of $f$ waves in lead $\mathrm{VI}$, the operative results, and the adequacy of maintenance therapy with quinidine or procainamide.

\section{Results}

Patients in sinus rhythm before mitral valvotomy (Tables $I$ and 2) There were 30 patients in sinus rhythm before operation; during or shortly after operation, I4 developed atrial fibrillation: 4 of these returned to sinus rhythm without electrical defibrillation, spontaneously in 2 cases, and with the administration of small doses of quinidine in preparation for planned defibrillation in the other 2 ; all of these remain in sinus rhythm 3 to 5 years later. Ten patients remained in atrial fibrillation, and 9 of these were successfully defibrillated electrically; the other had a technically poor valvotomy and defibrillation was not attempted.

Of the 9 defibrillated patients, 5 returned to atrial fibrillation within 6 months: one of these had previously fibrillated and been restored to sinus rhythm with quinidine before operation (a second valvotomy); one had previously had paroxysmal atrial fibrillation; the other 3 had technically unsatisfactory valvotomies resulting in important mitral regurgitation and one also had severe aortic valve disease. One other patient with paroxysmal atrial fibrillation remained basically in sinus rhythm for $\mathrm{I}_{4} \frac{1}{4}$ years, before fibrillation became established. Two patients reverted to atrial fibrillation after $2 \frac{3}{4}$ years and $3 \frac{1}{2}$ years, and the last remains in sinus rhythm at $3 \frac{1}{4}$ years.

Of the 16 patients remaining in sinus rhythm after valvotomy, I was lost to followup, but the other 15 all remained in sinus rhythm for at least 2 years. Only 2 have since reverted to atrial fibrillation; the remainder (I3) were still in sinus rhythm when last seen, in 12 cases more than 3 years later, and in 9 cases more than 4 years later.

Patients in atrial fibrillation before mitral valvotomy (Tables $I$ and 3 ) There were 70 patients in atrial fibrillation before operation; 3 of these returned to sinus rhythm with the administration of small doses of quinidine in preparation for planned defibrillation, and one reverted spontaneously 24 hours after unsuccessful DC defibrillation. Twenty patients were not defibrillated for various reasons; 9 died in hospital shortly after operation, or fared badly, dying within weeks or a few months of operation; I patient had a torn valve, requiring early mitral valve replacement; I refused; in the other 9 the operation was a second or third valvotomy (4 cases), or atrial fibrillation had been present for more than 5 years ( 7 cases).

DC fibrillation was attempted in all the remaining 47 patients. Though sinus rhythm was restored in 29 of these, only 15 remained in normal rhythm on discharge from hospital, 6 at $\mathrm{I}$ year, and 4 at 2 years. It was found that the duration of sinus rhythm after defibrillation was most closely related to the duration of atrial fibrillation before operation.

Duration of atrial fibrillation (Table 4) The longer atrial fibrillation had been present before valvotomy, the lower was the immediate success rate for electrical defibrillation, and the fewer the patients remaining in sinus rhythm after any specified period of followup. Thus, no patient remained in sinus rhythm for more than a year who had been fibrillating for more than a year before operation. Defibrillation was immediately successful in only 50 per cent of 24 patients whose arrhythmia had been present for more than 5 years; atrial fibrillation returned within only

TABLE 2 Analysis of 30 patients in sinus rhythm before mitral valvotomy

\begin{tabular}{|c|c|c|c|c|c|c|c|c|}
\hline & \multirow{2}{*}{$\begin{array}{l}\text { No. of } \\
\text { patients }\end{array}$} & \multicolumn{7}{|c|}{ No. of patients remaining in sinus rhythm } \\
\hline & & $\begin{array}{l}\text { Immed. } \\
\text { after } \\
\text { defib. }\end{array}$ & $\begin{array}{l}\text { Hospital } \\
\text { discharge }\end{array}$ & $\begin{array}{l}3 \\
m t h\end{array}$ & $\begin{array}{l}6 \\
m t h\end{array}$ & $\begin{array}{l}I \\
y r\end{array}$ & $\begin{array}{l}2 \\
y r\end{array}$ & $\begin{array}{l}\text { Last } \\
\text { exam. }\end{array}$ \\
\hline $\begin{array}{l}\text { Remained in SR postop. } \\
\text { Atrial fib. postop.: spontaneous return }\end{array}$ & 16 & - & 16 & I6 & $15^{\star}$ & $15^{\star}$ & $15^{\star}$ & $13^{\star}$ \\
\hline $\begin{array}{l}\text { to sinus rhythm ( } \pm \text { quinidine) } \\
\text { Atrial fib. postop. } \\
\text { Not defibrillated }\end{array}$ & $\begin{array}{r}4 \\
10 \\
1\end{array}$ & - & 4 & 4 & 4 & 4 & 4 & 4 \\
\hline DC defibrillation & 9 & 9 & 7 & 6 & 4 & 4 & 3 & $\mathbf{I}$ \\
\hline
\end{tabular}

* I case lost to follow-up. 
TABLE 3 Analysis of 70 patients in atrial fibrillation before mitral valvotomy

\begin{tabular}{|c|c|c|c|c|c|c|c|c|}
\hline \multirow[b]{2}{*}{ 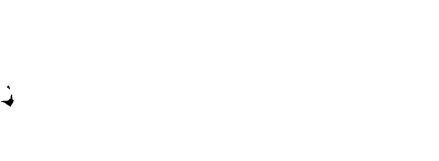 } & \multirow{2}{*}{$\begin{array}{l}\text { No. of } \\
\text { patients }\end{array}$} & \multicolumn{7}{|c|}{ No. of patients remaining in sinus rhythm } \\
\hline & & $\begin{array}{l}\text { Immed. } \\
\text { after } \\
\text { defib. }\end{array}$ & $\begin{array}{l}\text { Hospital } \\
\text { discharge }\end{array}$ & $\begin{array}{l}3 \\
m t h\end{array}$ & $\begin{array}{l}6 \\
m t h\end{array}$ & $\begin{array}{l}I \\
y r\end{array}$ & $\begin{array}{l}2 \\
y r\end{array}$ & $\begin{array}{l}\text { Last } \\
\text { exam. }\end{array}$ \\
\hline $\begin{array}{l}\text { Spontaneous return to sinus rhythm } \\
\text { DC defibrillation } \\
\text { Not defibrillated }\end{array}$ & $\begin{array}{l}4^{\star} \\
47^{\star} \\
20\end{array}$ & $\overline{29}$ & $\begin{array}{r}3 \\
16 \\
-\end{array}$ & $\begin{array}{l}2 \\
9 \\
-\end{array}$ & $\begin{array}{l}0 \\
8 \\
-\end{array}$ & $\begin{array}{l}\circ \\
6 \\
-\end{array}$ & $\begin{array}{l}\circ \\
4 \\
-\end{array}$ & $\begin{array}{l}0 \\
2 \\
-\end{array}$ \\
\hline
\end{tabular}

* Includes I patient unsuccessfully defibrillated 24 hours before spontaneous reversion.

$\approx$

TABLE 4 Relation of result of defibrillation to duration of atrial fibrillation

\begin{tabular}{|c|c|c|c|c|c|c|c|c|}
\hline \multirow{2}{*}{$\begin{array}{l}\text { Pre- and postoperative rhythm } \\
\text { Duration of atrial fibrillation }\end{array}$} & \multirow{2}{*}{$\begin{array}{l}\text { No. of } \\
\text { patients }\end{array}$} & \multicolumn{7}{|c|}{ No. of patients remaining in sinus rhythm } \\
\hline & & $\begin{array}{l}\text { Immed. } \\
\text { after } \\
\text { defib. }\end{array}$ & $\begin{array}{l}\text { Hospital } \\
\text { discharge }\end{array}$ & $\begin{array}{l}3 \\
m t h\end{array}$ & $\begin{array}{l}6 \\
m t h\end{array}$ & $\begin{array}{l}I \\
y r\end{array}$ & $\begin{array}{l}2 \\
y r\end{array}$ & $\begin{array}{l}\text { Last } \\
\text { exam. }\end{array}$ \\
\hline SR preop. and postop. ${ }^{\star}$ & 20 & 一 & 20 & 20 & 19 & 19 & 19 & 17 \\
\hline SR preop., atrial fib. postop. & 9 & 9 & 7 & 6 & 4 & 4 & 3 & I \\
\hline Atrial fib. preop. $<6$ mtht & 8 & 8 & 5 & 4 & 4 & 3 & 2 & $\mathbf{I}$ \\
\hline Atrial fib. $6 \mathrm{mth}-1$ yr $\ddagger$ & 9 & 6 & 6 & 4 & 4 & 3 & 2 & $\mathbf{I}$ \\
\hline Atrial fib. $\mathrm{I}-5 \mathrm{yr}$ & 6 & 3 & 3 & I & 0 & 0 & 0 & 0 \\
\hline Atrial fib. $>5$ yr & 24 & 12 & 2 & 0 & 0 & 0 & 0 & 0 \\
\hline
\end{tabular}

* Includes 4 patients transiently in atrial fibrillation after valvotomy but not requiring defibrillation.

t Excludes I patient spontaneously returning to sinus rhythm.

¥ Excludes 2 patients spontaneously returning to sinus rhythm.

a few beats, a few minutes, or a few hours in over a half, and sinus rhythm persisted for no more than 5 weeks in any of this group. On the other hand, of 17 patients fibrillating for less than a year, 6 maintained sinus rhythm for I year (though one had paroxysmal atrial fibrillation), and 4 for 2 years. These results are shown graphically in the Figure which shows also the fate of those patients in sinus rhythm both before and after operation, and those in sinus rhythm before and atrial fibrillation after operation; also included are 8 patients returning spontaneously to sinus rhythm with or without a small dose of quinidine.

Other factors influencing results of defibrillation Since none of those patients whose fibrillation had been present for more than I year before operation maintained sinus rhythm for more than a short time after electrical defibrillation, these are excluded from further consideration. The group remaining consists of 29 patients, and includes (a) 9 patients in sinus rhythm preoperatively and atrial fibrillation postoperatively, all successfully defibrillated, and (b) 20 patients fibrillating for less than a year, who were either defibrillated (17) or reverted spontaneously to sinus rhythm (3).

Age and sex The result (i.e. the length of time for which sinus rhythm was maintained) was not significantly influenced by the age of the patient: only those few patients under 40 appeared to do slightly better, those over 60 slightly less well than average. The result was, however, better in women (one-third still in sinus rhythm at 2 years) than in men (only one-tenth still in sinus rhythm at 2 years).

Result of valvotomy In a few patients, an unsatisfactory valvotomy was followed by a failed defibrillation or rapid return to atrial fibrillation, but some patients with a moderate degree of postoperative mitral regurgitation maintained sinus rhythm for over 2 years. Eight patients with calcified valves all fibrillated again within 6 months. Only I of 4 patients undergoing a second closed valvotomy remained in sinus rhythm for 6 months.

Heart size Only 3 patients in this group had a cardiothoracic ratio of 60 per cent or more, and all had returned to atrial fibrillation 


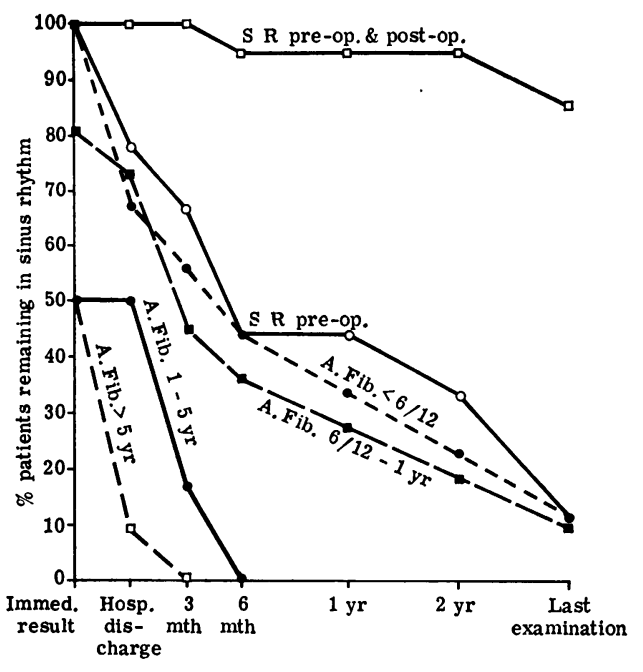

FIG Duration of sinus rhythm after mitral valvotomy related to preoperative rhythm and duration of preoperative atrial fibrillation.

(a) twenty patients in sinus rhythm before and after operation ( $\square-\square$ ), includes 4 patients transiently in atrial fibrillation after valvotomy, but not requiring defibrillation. (b) Nine patients in sinus rhythm before, and atrial fibrillation after operation, all electrically defibrillated $(\mathrm{O}-\mathrm{O})$. (c) Nine patients in atrial fibrillation less than 6 months before operation (•- - $\bullet$ ); this group includes 8 electrically defibrillated and one returning spontaneously to sinus rhythm. (d) Eleven patients in atrial fibrillation for between 6 months and I year before operation (-); this group includes 9 patients in whom defibrillation was attempted, and 3 patients returning spontaneously to sinus rhythm (I after failed defibrillation). (e) Six patients in atrial fibrillation between $I$ and 5 years before operation (๑- $\bullet)$. ( $f$ ) Twenty-four patients in atrial fibrillation more than 5 years before operation $\square---\square$.

within 3 months. (Fifteen of the 30 patients whose fibrillation had been present for more than a year had cardiac enlargement of this degree; only one of these remained in sinus rhythm at 3 months, but was fibrillating again within 6 months.)

Energy requirements for defibrillation All but 4 patients were successfully defibrillated with I or 2 shocks (200 joules or less in all except $I$ ). None of the 4 patients requiring 3 or 4 shocks maintained sinus rhythm for more than a few beats.
Amplitude of $f$ waves in lead VI was classified as fine (most $f$ waves $0.1 \mathrm{mV}$ or less), medium (average $f$ wave amplitude $0.1-0.2$ $\mathrm{mV}$ ), or coarse (most $f$ waves more than 0.2 $\mathrm{mV}$ ). Of 7 patients with fine $f$ waves, only 2 remained in sinus rhythm at I year, and only $I$ at 2 years. Of 22 patients with medium or coarse $f$ waves, 8 remained in sinus rhythm at $I$ year and 6 at 2 years. (Of the 30 patients in atrial fibrillation for more than $I$ year before mitral valvotomy, 80 per cent showed fine $f$ waves in VI.)

Maintenance treatment with antiarrhythmic agents It is not possible from our data to relate reversion to atrial fibrillation to adequacy or inadequacy of quinidine or procainamide prophylaxis.

Experience with repeated defibrillation A second defibrillation was carried out in 6; one of these patients was defibrillated 3 times, and another on 4 separate occasions. One maintained sinus rhythm for only 3 months after mitral valvotomy and defibrillation, but then required mitral valve replacement and after a second defibrillation has remained in sinus rhythm for more than 3 years. One patient with paroxysmal atrial fibrillation was defibrillated at $\mathrm{I} \frac{1}{4}$ years when a paroxysm failed to remit spontaneously, but paroxysmal atrial fibrillation continued for another $I \frac{1}{2}$ years when fibrillation became permanent. In the other 4 patients, the duration of maintained sinus rhythm after defibrillation became shorter with each subsequent electroconversion.

\section{Discussion}

These results clearly show that only a small proportion of an unselected group of patients defibrillated electrically after mitral valvotomy can be expected to remain in sinus rhythm for more than a few weeks. The chance of maintaining sinus rhythm for even 6 months in a patient who has been fibrillating for more than a year before operation is so small that the attempt is not worth making. When atrial fibrillation has been present for less than a year, or has appeared for the first time in the postoperative period, a small but significant proportion of patients remains in sinus rhythm for a worth-while period: roughly two-fifths at 6 months, one-third at I year, and one-quarter at 2 years. Though duration of atrial fibrillation is the most important factor influencing the maintenance of sinus rhythm after countershock, other unfavourable features are low amplitude $f$ waves in lead VI, cardiomegaly, and male sex. Sinus 
rhythm is less likely to be maintained after an unsatisfactory or second valvotomy, but moderate postoperative mitral regurgitation does not preclude a successful defibrillation. The duration of atrial fibrillation has previously been observed to influence the immediate success rate of electroconversion (Halmos, 1966; Lown, 1967; Resnekov and McDonald, I968) and the influence of small $f$ waves on the conversion rate after DC countershock ( $\mathrm{Hal}-$ mos, 1966; Lown, 1967) and quinidine (Aber, 1962) has also been recorded.

It is our current practice, therefore, to advise electrical defibrillation when atrial fibrillation has been present for less than a year, unless the heart is very large (CTR more than $60 \%$ ), or mitral valvotomy has produced severe regurgitation. If conversion is not achieved with a shock of 200 joules or less, there is little point in employing higher energies. A few patients maintain sinus rhythm for I or more years after successful defibrillation. In these, the question of a second defibrillation arises; though limited experience suggests that sinus rhythm rarely persists more than a few months after a suc-

- cessful repeat defibrillation, this is certainly worth attempting.

The onset of atrial fibrillation is an event in the natural history of rheumatic heart disease, probably determined more by the degree of atrial myocardial damage and injury to the sinoatrial node (Hudson, I960) than by the severity of the valve disease. Atrial fibrillation may be paroxysmal before becoming established; in other cases atrial fibrillation may be provoked by intercurrent illness, often a respiratory infection. If a sinus mechanism returns, either spontaneously or with treatment, normal rhythm may persist for some months or a year or two before atrial fibrillation becomes established. The occur-

- rence of either paroxysmal atrial fibrillation or transient fibrillation in the course of an infection usually means that the arrhythmia will recur and become established before long. It seems likely that a cardiac operation, such as mitral valvotomy, will precipitate atrial fibrillation only in those patients in whom there is already a damaged sinoatrial node and the onset of atrial fibrillation is already impending. If this view is correct, it cannot be expected that sinus rhythm will be maintained for long even if successfully restored after valvotomy. Furthermore, if atrial fibrillation is already present before , operation, the maintenance of sinus rhythm postoperatively will depend on the state of the sinus node and atrial myocardium, and be influenced only marginally by the success- ful surgical relief of mitral stenosis. Conversely, those patients with relatively undamaged node and atrial wall are much less likely to develop atrial fibrillation at or immediately after mitral valvotomy, and may well remain in sinus rhythm for several years after operation. This hypothesis accords well with our observations, and does not encourage an attempt to find more effective antiarrhythmic drugs in this situation. Though the prophylactic use of quinidine may be valuable in paroxysmal atrial fibrillation, its value in preventing the return of atrial fibrillation after defibrillation is disputed. Though Härtel $e t$ al. (1970) showed that quinidine delayed the return of atrial fibrillation, their period of follow-up extended for 3 months only. It seems unlikely that quinidine or any other drug will be effective in increasing the duration of maintained sinus rhythm for more than a few weeks or months.

We wish to thank Dr. F. Navab and Dr. Brenda Dudley who started the follow-up on these patients. We are also indebted to Mr. J. R. Belcher who performed most of the valvotomies.

\section{References}

Aber, C. P. (I962). Quinidine therapy after mitral valvotomy. Thorax, 17, 274.

Benchimol, A., Lowe, H. M., and Akre, P. R. (1965). Cardiovascular response to exercise during atrial fibrillation and after conversion to sinus rhythm. American Fournal of Cardiology, 16, 31.

Bloom, V. R. (I963). The prognosis of atrial fibrillation following mitral valvotomy. British Heart fournal, 25, 595 .

Gilbert, R., and Cuddy, R. P. (1965). Digitalis intoxication following conversion to sinus rhythm. Circulation, 32, 58.

Goldman, M. J. (1960). The management of chronic atrial fibrillation: indications for and method of conversion to sinus rhythm. Progress in Cardiovascular Diseases, 2, 465.

Graettinger, J. S., Carleton, R. A., and Muenster, J. J. (1964). Circulatory consequences of changes in cardiac rhythm produced in patients by transthoracic direct-current shock. Fournal of Clinical Investigation, 43, 2290.

Halmos, P. B. (I966). Direct current conversion of atrial fibrillation. British Heart fournal, 28, 302.

Härtel, G., Louhija, A., Konttinen, A., and Halonen, P. I. (I970). Value of quinidine in maintenance of sinus rhythm after electric conversion of atrial fibrillation. British Heart fournal, 32, 57.

Hudson, R. E. B. (1960). The human pacemaker and its pathology. British Heart fournal, 22, 153.

Kahn, D. R., Wilson, W. S., Weber, W., and Sloan, H. (I964). Hemodynamic studies before and after cardioversion. Fournal of Thoracic and Cardiovascular Surgery, 48, 898.

Killip, T., and Baer, R. A. (1966). Hemodynamic effects after reversion from atrial fibrillation to sinus rhythm by precordial shock. Fournal of Clinical Investigation, 45, 658 .

Kleiger, R., and Lown, B. (1966). Cardioversion and digitalis: II. Clinical studies. Circulation, 33, 878 . 
Lown, B. (1967). Electrical reversion of cardiac arrhythmias. British Heart fournal, 29, 469.

Lown, B., Amarasingham, R., and Neuman, J. (1962). New method for terminating cardiac arrhythmias. Use of synchronized capacitor discharge. Fournal of the American Medical Association, 182, 548.

Morris, J. J., Entman, M., North, W. C., Kong, Y., and McIntosh, H. (1965). The changes in cardiac output with reversion of atrial fibrillation to sinus rhythm. Circulation, 31, 670.

Oram, S., and Davies, J. P. H. (1964). Further experience of electrical conversion of atrial fibrillation to sinus rhythm: analysis of 100 patients. Lancet, $\mathbf{r}$, 1294.

Resnekov, L. (1967). Haemodynamic studies before and after electrical conversion of atrial fibrillation and flutter to sinus rhythm. British Heart fournal, 29, 700 .

Resnekov, L., and McDonald, L. (1968). Appraisal of electroconversion in treatment of cardiac dysrhythmias. British Heart fournal, 30, 786.
Resnekov, L., Waich, S., Gibson, D., and McDonald, L. (1969). Use of long-acting quinidine in maintaining sinus rhythm after electroconversion of atrial dysrhythmias. In Proceedings of the British Cardiac Society. British Heart Fournal, 31, 395.

Rossi, M., and Lown, B. (1967). The use of quinidine in cardioversion. American fournal of Cardiology, 19, 234.

Selzer, A., Kelly, J. J., Gerbode, F., Kerth, W. J., Blackley, J. E., Morgan, J. J., and Keyani, K. (1965). Treatment of atrial fibrillation after surgical repair of the mitral valve. Annals of Internal Medicine, 62, 1213.

Szekely, P. (1964). Systemic embolism and anticoagulant prophylaxis in rheumatic heart disease. British Medical fournal, 1, 1209.

Towers, M. K., Gibson, R. V., Burn, J. M. B., and Monro, J. A. (1965). The termination of cardiac arrhythmias by direct current shock. Postgraduate Medical fournal, 41, 120. 